\title{
Gluten-hydrolyzing probiotics: An emerging therapy for patients with celiac disease (Review)
}

\author{
DEVARAJA GAYATHRI and ALURAPPA RAMESHA \\ Department of Microbiology, Davangere University, Davangere, Karnataka 577007, India
}

Received April 6, 2020; Accepted June 18, 2020

DOI: $10.3892 /$ wasj.2020.55

\begin{abstract}
Celiac disease (CD), also known as gluten-sensitive enteropathy, is an autoimmune disorder characterized by variable malabsorption syndrome with characteristics, such as chronic diarrhea, weight loss and abdominal distention. Possible therapies for CD include dietary and non-dietary strategies; the latter include permeability inhibition and tissue transglutaminase (tTG) blockage using chemotherapeutic drugs. Dietary strategies for the management of CD include a gluten-reduced diet, and the supplementation of probiotics and their products. The gluten-reduced diet is not always sustainable due to the availability of gluten-free nutritional commodities. In this context, probiotics are live microorganisms and their products are supplemented to the patients in order to improve their overall well-being. The effects of probiotics on gut health varies from species to species, and it is dependent on environmental factors and other commensals present in the gut. The ameliorating effects of probiotics include the detoxification of gluten peptides, the strengthening of the intestinal epithelial barrier and the degradation of toxin receptors, adhesion to intestinal mucosa, the competitive exclusion of pathogens, the production of inhibitory substances against pathogens, and the regulation of immunity and attenuation of the inflammation associated with a Toll-like receptor through immunomodulation. These observations suggest that a combination of specific gut microbiota and probiotics may prove to be beneficial for patients with $\mathrm{CD}$. In this context, the present review focuses on the prevalence and implications of the disease, as well as the mechanisms of the effects of probiotics, which may aid in the development of natural food adjuncts for individuals prone to or with $\mathrm{CD}$.
\end{abstract}

Correspondence to: Professor Devaraja Gayathri, Department of Microbiology, Davangere University, Shivagangothri, Davangere, Karnataka 577007, India

E-mail: gayathridevaraja@gmail.com

Key words: celiac disease, gluten, gluten allergy, gut microbiota, probiotic, therapy

\section{Contents}

1. Introduction

2. Implications of celiac disease on human health

3. Role of peptides in the development of celiac disease

4. Diagnosis of celiac disease

5. Possible therapies for celiac disease

6. Importance of microorganisms in the treatment of celiac disease

7. Mechanisms of action of probiotics in celiac disease

8. Commonly available commercial probiotics

9. Conclusion

\section{Introduction}

Celiac disease (CD) is an unusual malabsorption syndrome, an autoimmune enteropathy among genetically susceptible individuals. CD has been known as an abdominal disorder and has long been listed in the medical lexicon. It was first described in the first century A.D. by Aretaeus Cappadocia, a contemporary of the Roman physician, Galen, using the Greek term 'koeliakos' (suffering of the bowels) (1). At a later date, Samuel Gee (1880), a British physician, defined CD as a type of chronic indigestion in humans (2). The cause of the disease, specifically distinct from other digestive disorders and their symptoms, has been studied over the past 4 decades (3). Initially, it was reported to be prevalent in western part of the world, although its distribution is found globally. This disease has become a very common lifetime disorder among individuals with a prevalence of 0.5 to $1 \%$ worldwide (4). However, the World Gastroenterology Organization (WGO) suggests that the female to male for CD is 2:1. Serological studies using anti-gliadin, anti-endomysium or anti-transglutaminase antibody assays, which are hallmark tests for $\mathrm{CD}$, have demonstrated a high prevalence of CD noted in the Middle East, North Africa and India (5,6). In India, the number of cases with CD has exhibited an increasing trend recently and perhaps coincides with a large intake of gluten-rich foods (6). Currently, due to the prevalence of diabetes, Southern Indians also prefer wheat as a staple food, unlike previously. This may also be one of the reasons for the observed increase in the number of cases of CD in India. Therefore, the Indian Task Force for Celiac Disease directed and encouraged research on the prevalence and diagnosis of $\mathrm{CD}$. It has also made the 
regulations for the marking of gluten-free/reduced products and subsidies on these foods, and has stated that these foods should be sold at a reasonable price in order to be widely available to patients with $\mathrm{CD}(7,8)$. Moreover, there is a great demand for gluten-free/reduced food for the prevention and management of CD in India. In this regard, the present review article highlights the exploration of gluten-hydrolyzing probiotics as another important management strategy for patients with $\mathrm{CD}$.

\section{Implications of celiac disease on human health}

$\mathrm{CD}$, is referred to by various terms, such as celiac sprue, non-tropical sprue, idiopathic sprue, idiopathic steatorrhea and gluten enteropathy. CD is observed as a permanent intolerance to the storage proteins of wheat, rye and barley among human leucocyte antigen (HLA)-DQ2/DQ8-positive individuals (9). This condition has been characterized by complex adaptive and innate immune responses that yield characteristic chronic inflammation and villous atrophy in the small intestine, as well as systemic inflammation with the deposition of disease-specific auto-induced antibodies in various parts of the body (10). CD can manifest in individuals with a previously unexpected range of clinical symptoms consisting of malabsorption syndrome with chronic diarrhea, weight loss and abdominal distention, affecting the intestine as a primary site of the disease, leading to the destruction of any organ and/or the digestive system of the body and consequent multisystemic disorder $(3,11)$. In addition, CD has been associated with a number of complications, mainly including malignancy and autoimmune disorders (12), which can lead to an improper diagnosis with tropical sprue, particularly due to overlapping or with atypical symptoms. CD can be diagnosed by the detection of autoantibodies generated upon the ingestion of gluten or by a bowel biopsy examination. In addition to this, the incidence of $\mathrm{CD}$ has been found to be associated with diabetes or hypothyroidism, and or chronic liver disease when compared to tropical sprue (7). Typical disease symptoms include metabolic bone disease, malnutrition, iron-deficient anemia, chronic diarrhea, abdominal bloating and distention, weight loss, damage to the jejuna mucosa and others (13). Conventionally, anemic patients are generally examined for CD. Typical asymptomatic patients with iron deficiency anemia have been evaluated by serological testing and have been found to exhibit a prevalence of CD ranging from 2.3 to $5.0 \%$ (14), and in some cases even between 10.3 to $15 \%$ (15). Further research has also indicated the prevalence of CD among premenopausal women with iron deficiency anemia (16). It has also been associated with liver disease, hypertransaminasemia and with a high risk of neuro-psychiatric disorders, such as peripheral neuropathy, mood swings, psychosis and epilepsy (17).

Gluten is rich in proline and glutamine residues, and therefore escapes proteolysis by human digestive enzymes, which lack post-prolyl endopeptidase activity. Thus, partially digested gluten peptides are deposited in the intestinal epithelial lumen and thus increase permeability by binding to CXCR3 receptors, and enter the lumen (18). Upon this entry process, the peptides undergo deamidation at glutamine residues by tissue transglutaminase (tTG) in the lamina propria region. The deamidated peptides bind to HLA-DQ2/DQ8 molecules with a greater affinity to gluten reactive $\mathrm{CD} 4^{+} \mathrm{T}$ cells, activating the immune response $(18,19)$. Notably, although one third of the Western population carries these HLA alleles (20), fortunately, only 3\% develops CD, indicating that HLA-DQ2/DQ8 is necessary, but not sufficient for the development of the disease (4). Noticeably, 90 to $95 \%$ of individuals with CD express HLA-DQ2, and only 5 to $10 \%$ express HLA-DQ8 (19).

Although, the significant link between $C D$ and HLA-DQ2/DQ8 has been established, CD is not present at the time of birth or before the consumption of gluten in diet (4) and generally does not appear before the age of 2 years, even in individuals expressing HLA-DQ2/DQ8 $(21,22)$. In recent years, the prevalence of CD seems to have doubled and has been attributed to the environment, such as the administration of a gluten-rich diet to infants and the occurrence of certain gastrointestinal infections and immunological factors. It has been reported that breast-feeding for a long period of time and the delay in the ingestion of gluten-based food can perhaps postpone the onset of CD, particularly in young children (8). The occurrence of CD among children aged up to 4 months has not been observed upon the consumption of a gluten-rich diet; however, children at 7 months old have been found with autoimmunity $(8,19)$.

\section{Role of peptides in the development of celiac disease}

The development of CD may be attributed to HLA. Two peptides that present HLA-DQ molecules, DQ ( $\alpha 1 * 0501$, $\left.\beta 1^{*} 02\right) / \mathrm{DQ} 2$ or sometimes often DQ $\left(\alpha 1^{*} 03, \beta 1^{*} 0302\right) / \mathrm{DQ} 8$, present on antigen-presenting cells (APCs), are the major genetic factors responsible for CD. HLA-DQ2, a heterodimer, found in $90 \%$ of patients with CD, is generally expressed in a cis/trans form (23). However, DR3 haplotypes exist in cis form; where HLA-DQ alleles HLA-DQA $1 * 05$ encode $\alpha$ chain and HLA-DQB1*0201 encodes a $\beta$ chain of the dimer. A1-B8-DR3 is a classical Caucasian haplotype, whereas A26-B8-DR3 and Ax-B21-DR3 are typical haplotypes of CD in India (24). In trans form, DR7 haplotypes are related to the DQB1*0202 allele which encodes the $\beta$ chain. The DR11, DR12 or DR 13 haplotype with the HLA-DQA1*05 allele on other chromosomes encode the $\alpha$ chain, and the $\alpha$ and $\beta$ chains then unite to form CD-associated dimer. The $\alpha$ and $\beta$ chains are encoded by HLA-DQA1*03 and HLA-DQB1*0302, respectively, in the case of HLA-DQ8 (25). In cis form, the $\alpha$ and $\beta$ chains of DQ2 have been shown to be expressed by the HLA DQA $1 * 0501$ and HLA DQB1*0201 alleles of the DR3 haplotype. However, in trans form, the HLA DQA1*0501 allele of the DR5 haplotype encodes the $\alpha$ chain and DR7 haplotype with the DQB1*0202 allele on other chromosomes that encodes the $\beta$ chain. Furthermore, these two chains are united to form the HLA DQ2 molecule on APCs (18).

Role of gluten and $t T G$ in $C D$. Glutenin and gliadin are major protein fractions of wheat gluten. Gliadin fractions are more immunogenic than glutenin as they have more glutamine and proline residues. In addition, glutenin peptide epitopes are capable of activating DQ8-restricted T cell proliferation with QGYYPTSPQQS residues (26). Based on these amino acid sequences, are gliadins grouped into $\alpha, \gamma$ and $\omega$. These gliadins contain epitopes that exhibit an intense affinity 
towards DQ2/DQ8 molecules on APCs and are selectively accepted by gliadin-reactive $\mathrm{T}$ cells, which are only observed in the intestinal mucosa of CD-prone individuals (27). Three gliadin-derived DQ2-restricted epitopes, such as DQ2- $\alpha$-I-gliadin, DQ2- $\alpha$-II-gliadin and DQ2- $\gamma$-I-gliadin, and 2 DQ8-restricted epitopes, DQ8- $\alpha$-I-gliadin and DQ8-I-glutenin, are recognized by gut $\mathrm{T}$ cells $(26,28)$.

Gluten peptides become resistant to gastric, pancreatic and intestinal protease activity due to the high proline content and therefore enhance their retention in the small intestine. Furthermore, through epithelial transcytosis otherwise increases epithelial tight junction permeability, these gluten peptides reach the lamina propria and stimulate the tTG-mediated deamidation process $(11,29)$. In this context, tTG catalyzes selective crosslinking or the deamidation of protein-bound specific glutamine residues; in addition, acidic $\mathrm{pH}$ in the stomach leads to the random deamidation of a number of peptides (29).

When genetically susceptible individuals ingest proline-rich gluten, the generation of gluten peptides occurs. These gluten peptides are not catalyzed by proteases and enter the lamina propria to form the crosslinking tTG that leads to deamidation. Deamidated peptides contain more immunostimulatory epitopes and are presented to gluten-reactive CD4 T-cells by HLA-DQ2/DQ8. Subsequently, these activated T-cells produce autoantibodies and other immunological mediators, which may lead to tissue damage [increased permeability, the dysfunction of intestinal tight junctions, infiltration of intraepithelial lymphocytes (IELs), the flattening of villi, and inflammation and malabsorption, as in late phase of the pathogenesis of $\mathrm{CD}](18)$.

Fate of deamidated peptides and HLA-DQ2/DQ8. Deamidated gluten peptides with more negatively charged residues bind to HLA-DQ2 or HLA-DQ8 molecules with a high intensity. $\mathrm{T}$ cells that recognize the majority of DQ2-specific gliadin epitopes are tTG-targeted residues (26). A higher amount of glutamine and proline present in glutenins and gliadins of wheat gluten function as ideal substrates for TG2. The conversion of glutamine to glutamic acid residues through the deamidation process perhaps leads to a relatively large number of negatively charged residues of gliadin peptides. However, the affinity between gliadin epitopes and the peptide binding motif of HLA DQ2/DQ8 is crucial and leads to $T$ cell proliferation $(18,19)$. In corroboration, deamidated peptide-specific $\mathrm{T}$ cell proliferation has been clearly observed when $T$ cells are mixed with deamidated peptide and incubated with monocyte-derived dendritic cells (30).

Moreover, $\mathrm{T}$ cells trigger the humoral-mediated immune response (HMIR) and thus stimulate $B$ cells to produce corresponding antibodies for gluten peptides and tTG, and also produce groups of cytokines such as interferon (INF) $-\gamma$, interleukin (IL)-1 $\beta$, tumor necrosis factor (TNF)- $\alpha$, IL- 6 and IL-8 at increased levels (31). These cytokines promote the development of enteric lymphocytes as cytotoxic cells and result in local inflammation. However, gluten-induced $\mathrm{T}$ cells trigger the immune system, affecting the synthesis of suitable immune components and decrease the production of IL-17 and IL-22, resulting in an adverse or abnormal mucosal structure. However, a gluten-reduced or -free food intake augments the secretion of IL-17 and IL-22 with better mucosal composition (32). Molecular approaches open up numerous strategies for the effective treatment of CD (19).

\section{Diagnosis of celiac disease}

The diagnostic criteria for CD from the European Society for Pediatric Gastroenterology, Hepatology, and Nutrition (ESPGHAN) were published during the 1990s (33). According to these criteria, the diagnosis was based on the morphological assessment of the small intestinal mucosa obtained at 3 distinct conditions, namely: i) Initial flat mucosa when the patient has ingested gluten; ii) improvement in the small intestinal mucosa upon the withdrawal of gluten from the diet; iii) deterioration of the mucosa with gluten challenge. In 1990, the criteria were revised for both childhood and adult CD when an individual is on a gluten diet, based on a small intestinal biopsy and typical histopathological morphology (34 and refs. therein). Furthermore, upon the complete restriction on gluten from the diet, there should be a full clinical response. However serological and biopsy analysis are gold standard tests (17). Histopathologically, CD presents a range in severity. Based on the severity of intestinal mucosal damage, several scoring systems for histological evaluation have been suggested (34).

Furthermore, antibodies, such as endomysial antibodies (EMA), tTG antibodies (tTGA) and antibiodies against gliadin (AGA) of the IgA-class are also significant diagnostic tools for $\mathrm{CD}$, among which EMA and tTGA are widely used. There is a high occurrence of CD among individuals with IgA deficiency (8\%). In addition, antibodies against gliadin can be measured by enzyme linked immunosorbent assay (ELISA) (15). Endomysium is a connective tissue protein found in the collagenous matrix of mucosal cells. Antibodies to endomysium can be measured using an immunochemical assay with monkey esophagus or human umbilical cord as a substrate in the diagnosis of CD. However, this test is costly and requires skilled personnel to perform. On the contrary, the measurement of tTGA using ELISA with guinea pig liver or human recombinant tTG as a substrate is less costly and more feasible than EMA (15).

The critical role of $\mathrm{CD}$ in the pathogenesis of $\mathrm{CD}$ is played by the HLA system; in particular, the role of HLA-DQ2/DQ8 in the development of $\mathrm{CD}$ has been well documented. As HLA-DQ2/DQ8 are heterodimers, in the majority of cases, carriers do not develop CD (40\%) and therefore, genetic tests for the diagnosis of CD have limited applications (19), but can be used to rectify the uncertain diagnosis.

\section{Possible therapies for celiac disease}

Non-dietary strategies. A number of non-dietary strategies, that include decreasing intestinal tight junction (TJ) permeability using TJ regulators, such as larazotide acetate, the inhibition of tTG activity, the use of corticosteroids, such as budesonide, and altering the structure of gliadin using sequestering polymers are preferred for the treatment of $\mathrm{CD}(35,36)$. Such innovative options pave the way for alternative or adjunctive therapy. However, the effectiveness of this strategy perhaps is uncertain in terms of safety, efficacy and longer duration, rendering monitoring difficult. Furthermore, the 


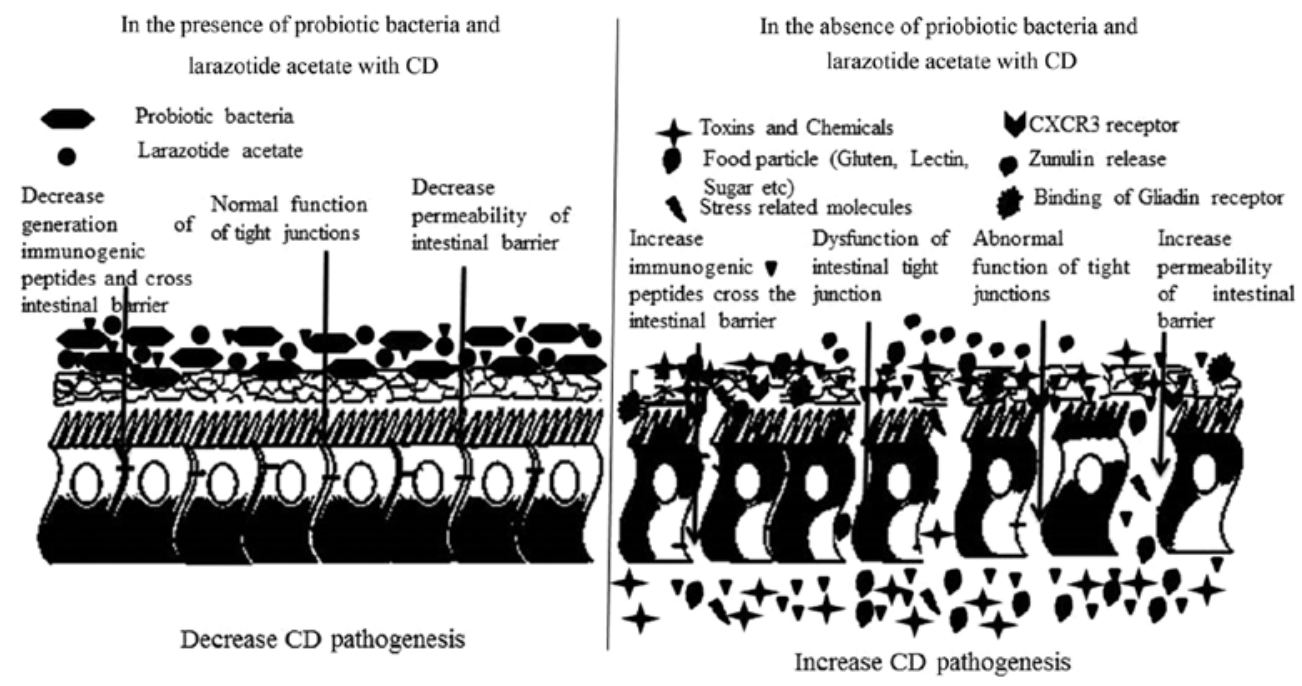

Figure 1. Effects of larazotide acetate on intestinal permeability (18).

follow-up of patients with $\mathrm{CD}$ with these therapeutic measures did not appear feasible (18). Intestinal TJ dysfunction leads to the increased permeability of intestinal barriers to gliadin peptides and exposes submucosal cells to immunogenic peptide-induced toxic effects. Larazotide acetate, a peptide regulating TJs, prevents the opening of intestinal epithelial TJs and has exhibited no severe adverse effects in clinical trials (Fig. 1) (36). The oral administration of this drug prior to each gluten intake perhaps helps to include the regulation of gluten-based food, alleviating the uncomfortable symptoms of $\mathrm{CD}$. This perhaps requires further validation for the improvement of the efficacy of the drug to reduce gastrointestinal symptoms.

tTG is one of the endomysial auto-antigens which block the catalytic activity against auto-immunization and reduces the deamidation of glutamine-rich content. In an in vitro and in situ study, IgG and IgA classes of antibodies from patients with CD inhibited tTG activity in a dose-dependent manner (35). By contrast, tTG activities are inhibited by anti-tTG antibodies, and when targeted to active sites with relatively higher concentrations, residual enzyme activity would be sufficient to induce pathogenesis (37). Budesonide is one of the corticosteroid drugs which is often used to reduce looseness of the bowels, inflammation and intestinal tissue damage. Furthermore, budesonide effectiveness was previously assessed for the treatment of adults with CD; a group of patients with malabsorption was administered a only gluten-free diet only and the other group was administered a gluten-free diet with budesonide on a daily basis; after 28 days, the subjects treated with both the gluten-free diet and budesonide exhibited better health compared to the group that was treated only with the gluten-free diet (35). Furthermore, Goerres et al (38) reported that the combination of immunomodulatory medications, such as the steroids, azathioprine and prednisone, can be used with corticosteroids for the treatment of a number of autoimmune diseases associated with CD. In addition, polyhydroxy ethyl methacrylate-co-styrene sodium sulfonate [P(HEMA-co-SS)] is a sequestering polymer (non-absorbable). This polymer at gastric $\mathrm{pH} 1.2$ and at intestinal $\mathrm{pH} 6.8$ reacts with $\alpha$ gliadin peptide and induces changes in configuration and thus forms larger complex particles; therefore, tTG fails to recognize structurally altered peptides. Sequestering the gliadins with the polymer prevents the enzymatic action and the progression of disease halts (36). Instead, it has been proposed that this polymer-sequestered peptide would be discharged from the body prior to entering the blood $(18,39)$.

Dietary strategies. Dietary therapy opted for the treatment of CD should be safe, effective and feasible with marginal or without side-effects. Nutritional dietary therapy involves a diet devoid of wheat, rye and barley. The presence of gluten in food could be reduced by biotechnological strategies using proteases produced by microbial cells, that hydrolyze immunogenic gluten peptides $(40,41)$.

These ideal strategies perhaps offer a potential alternative or adjunctive treatment options; however, they raise important questions of safety, efficacy and monitoring during long-term treatment. However, gluten-free dietary therapy has been found to be safe, and has become the mainstay of CD management.

Gluten-reduced diet. It is possible to reduce the gluten content by producing less immunogenic varieties of wheat or related crop and or other biotechnological approaches to hydrolyze immunogenic gluten peptides using microbial proteases. Several studies have revealed that the follow-up of a strict gluten-free diet reduces the pathogenicity of CD (8). However, this type of diet is difficult to adhere to by patients, as it requires the lifetime exclusion of gluten-rich food from their regular diet. In addition, the FAO/WHO-recommended standards specify that the quality factors for gluten-free foods should not exceed $20 \mathrm{mg} / \mathrm{kg}$. This consists of foods with ingredients from wheat (Triticum species), rye, barley, oats or other varieties. 'Gluten-free' foodstuffs substitute the original foodstuffs with the replacement of important basic nutrients with the same content of vitamins and minerals, and are produced under Good Manufacturing Practices (GMP) to avoid cross-contamination with prolamines. For this reason, patients with CD following a gluten-free diet, are recommended to take regular vitamin supplementation. Gluten-free fruits, vegetables and other food stuffs would also be consumed as a vitamin source or for micro nutrients. However, the availability 
of gluten-free food products according to dietary guidelines is limited in developing countries, and when available, these products are costly. Therefore, it is of utmost importance to develop gluten-reduced wheat foods using microorganisms. Moreover, the in vivo efficacy of microbial proteases or enzyme preparations, systematic delivery against gastric acid $\mathrm{pH}$ in the stomach, formulation and dosage are the main challenges that need to be met (42). Over the past decade, research in probiotic lactic acid bacteria has proven to be efficient in the treatment of metabolic disorders and several types of cancer $(40,43,44)$.

\section{Importance of microorganisms in the treatment of celiac disease}

The gut microflora has recently attracted attention again due to its critical role in health management and new concepts have been put forth regarding this by medical researchers (45). Consequently, the association between human health and the gut microbiota is significantly acknowledged and confirms that a healthy gut microflora is crucial for the comprehensive health of an individual (46). Over the period of host-microbial co-evolution, the intestine adjusts to bidirectional host-microbial exchange and also harbors a diverse microbiota which is separated by a single layer of epithelial cells. The interaction of the gut with its commensal microorganisms plays a crucial role in promoting homeostatic functions, such as immunomodulation, the upregulation of cytoprotective genes, the prevention and regulation of apoptosis, and the maintenance of barrier function, among others (46).

Several studies have reported that, at the epithelial level, a number of factors, such as the masking or modification of microbial-associated molecular patterns (MAPS) that are generally recognized by host receptors, as well as the inhibition of the NF- $\kappa$ B inflammatory pathway allow host cells to tolerate commensal microorganisms (47). Furthermore, some gut bacteria produce anti-inflammatory compounds, which result in a controlled inflammatory response, conferring protection against pathogens. Sometimes, the generation of a low-grade inflammatory response from commensal bacteria could be realized to boost the immune system against the pathogen (48). In addition, some gut bacteria produce a variety of metabolites ranging from relatively non-specific fatty acids, proteases with antimicrobial property and peroxides to highly specific bacteriocins (49). The gut microbiota, through these and other related mechanisms, have been found to play a crucial role in protecting the host from invading pathogens. These observations suggest that increasing the number of beneficial bacteria in the gut may be helpful in maintaining gut health and this could be achieved by the application of probiotics (19).

Supplementation of probiotics as an alternative treatment for $C D$. Microbiologists in the late 18th century identified that the gut microbiome of healthy individuals differed from that of infected individuals. The beneficial microorganisms found in the gut were termed as probiotics. The term probiotic means 'for life' and it currently refers to the beneficial effects on humans and animals. As per FAO/WHO (2001; http://www.fao. org/3/a-a0512e.pdf), probiotics were defined as living bacteria and when administered in an adequate quantity, confer health benefits to the host. However, the history of probiotics dates back to late 18th century. The credit for first observation made on the positive role of some selected bacteria was attributed to Eli Metchnikoff (1908). According to their findings, the bacterial community inhabiting the large intestine of humans was a source of toxic substances that were detrimental to the host, intoxicating the blood and contributing to the ageing process, leading to autointoxication (50).

In 1907, Metchnikoff had postulated that the natural fermentation of milk by lactic acid producing bacteria, i.e., Lactobacillus bulgaricus and Streptococcus thermophilus, prevented the growth of proteolytic species and therefore, lactic acid bacteria were used for the implantation of beneficial microbiota in the gastrointestinal tract. Furthermore, Fuller's (51) definition for probiotics reads as 'live microbial feed supplements which beneficially affect the host animal by improving its intestinal microbial balance'. Subsequently, Havenaar (52) corresponded to the probiotic definition with the following description: A viable mono or mixed culture of microorganisms which, applied to animals or man, beneficially affects the host by improving the properties of the indigenous microflora. At the end of the millennium, Salminen et al (53) proposed the following definition: 'Probiotics are microbial cell preparations or components of microbial cells that have a beneficial effect on the health and well-being of host'.

The probiotic microorganisms consist mostly of the strains of the genera Lactobacillus and Bifidobacterium, Bacillus, Pediococcus and others (54). Of note, the probiotic effect is strain-specific; i.e., different strains of the same species are always unique. Furthermore, they may differ in their adherence sites (site-specific) and may also exert specific immunological effects. Consequently, their action on a healthy and an inflamed mucosal milieu differs (55). Proposed mechanisms of probiosis include effects on the composition and function of the intestinal microbiome. Probiotics produce antimicrobial agents or metabolic compounds that suppress the growth of other microorganisms or compete for receptors and binding sites with other intestinal microorganisms on the intestinal mucosa (56), and thereby prevent the pathogen colonization. Probiotics strengthens the intestinal barrier, which may result in the maintenance of immune tolerance, and the decreased translocation of bacteria across the intestinal mucosa.

In addition, probiotics can modulate intestinal immunity and alter the responsiveness of the intestinal epithelia and immune cells to microorganisms in the intestinal lumen (57). Furthermore, the regulation of apoptosis and inflammatory action, the inhibition of procarcinogenic enzyme activity, and the induction of enzymatic activity that aids digestion and nutrient absorption enhances host health. These probiotic functions are the result of very complex mechanisms of consortia of microorganisms (58). Probiotics can also be found in dairy and non-dairy products. Probiotics are administered for the prevention and management of several diseases and disorders that mainly include traveler's diarrhea, rotavirus gastroenteritis, pouchitis, vaginosis, cirrhosis, hyperlipidemia, Helicobacter pylori infection, colitis, acute and chronic gastroenteritis, irritable bowel syndrome, inflammatory bowel disease and neonatal enterocolitis (59). In addition, maldigestion-related conditions, such as lactose intolerance, cow's milk protein allergy, soy protein allergy and gluten intolerance can also be treated and managed using probiotics (19). 
Detoxification of gluten peptides by probiotics and their proteases. There are two alternative gluten peptide hydrolysis strategies as follows: i) The medical approach which the hydrolyzation of immunogenic gluten peptides following ingestion in the gastrointestinal tract; and ii) the food technological approach which involves the to hydrolyzation of gluten peptide prior to the gluten ingestion during food processing (60).

i) Medical approach. Gluten degradation can be performed by prolyl endopeptidases of microbial sources that lend themselves to large-scale production (61). Prolyl endopeptidases (PEP), an endoproteolytic enzyme of microbial origin, can readily cleave proline-rich gluten epitopes in contrast to human digestive enzymes (62). Several researchers have reported the use of probiotics or their enzymes for gluten reduction in wheat foods. For example, on long-term wheat flour fermentation, VSL\#3 probiotic bacterial preparation has been shown to effectively reduce gluten toxicity; surprisingly, no increase in the infiltration of $\mathrm{CD}^{+}$intraepithelial lymphocytes was observed and moreover, a reduced zonulin release was observed when the jejuna of patients with $\mathrm{CD}$ was exposed to peptic-tryptic digest from VSL\#3 (40). Gluten-detoxifying gelatin-encapsulated capsules of Myxococcus xanthus prolyl endopeptidase (MX PEP) were characterized and developed to protect the gastric environment, with safe release into the duodenal region and a reduction in gluten-induced inflammation (41). An in vivo study reported that following the ingestion of gluten pre-treated with ALV003 to patients with CD, the gluten-specific $\mathrm{T}$ cell response was reduced compared to the placebo group (63). These studies clearly portrayed that microbial or probiotic proteases perhaps, used as an efficient tool to combat $\mathrm{CD}$ either by or other means.

Numerous studies have revealed the ability of prolyl endopeptidase from Flavobacterium meningosepticum in hydrolyzing the 33-mer gliadin peptide. Shan et al (64) also recommended the use of this enzyme for oral therapy for patients with $\mathrm{CD}$. Furthermore, these findings were supported by an in vivo study on rats, where PEP perfusion together with gluten peptides into the rat intestine accelerated the digestion of gluten by approximately 50 to $100 \%$ (61). In addition, Pyle et al (65) reported that the pre-treatment of gluten with PEP from F. meningosepticum, prevented the development of fat and carbohydrate malabsorption. PEP from Myxococcus xanthus, Sphingomonas capsulata $(41,64)$ and Lactobacillus helveticus (66), Bacillus sp. $(67,68)$ also supported gluten detoxification properties. However, Shan et al (64) mentioned that PEP were inactivated by pepsin and acidic conditions in the host stomach. Similarly, results were reported by Stepniak et al (69) for Aspergillus niger. This enzyme can be produced on a large scale at food-grade quality in industries at a reasonable cost and can be used as an oral supplementation in patients with $\mathrm{CD}$ to reduce the burden of ingested gluten (70).

ii) Food technological approach. Proteolysis by sourdough starter culture usage has become a novel approach with which to reduce gluten toxicity during food processing for patients with CD (71,72). In several studies, wheat flour fermentation with lactobacilli has been shown to decrease the CD-inducing effect of gluten (72). This observation has been extrapolated by Di Cagno et al (73) to produce sourdoughs that contain $30 \%$ of wheat flour and the remaining $70 \%$ of non-gluten flour with selected lactobacilli. The mixed starter (Lactobacillus alimentarius, L. brevis, L. sanfranciscensis and L. hilgardii), was able to hydrolyze gliadin fractions and the bread prepared from that sourdough was tolerated by patients with $C D$, which was proven by an intestinal permeability challenge. Furthermore, Di cagno et al (73) followed the same approach for preparing pasta for patients with CD. In another study, the combination of Lactobacillus alimentarius, L. brevis, L. sanfranciscensis and L. hilgardii were used as starter culture for pre-fermenting durum wheat semolina. The dough was then freeze-dried and mixed with buck wheat flour at a ratio of 3:7 and the pasta was prepared. The immunological assay of this sample has shown that the concentration of gluten has decreased from 6,280 to $1,045 \mathrm{ppm}$. However, this level of gluten was higher than the threshold levels as per the Codex Alimentarius Commission of WHO. According to Codex Alimentarius, foods containing gluten $<20 \mathrm{ppm}$ can be labeled as 'gluten-free', while products containing gluten $>20$ and up to $100 \mathrm{ppm}$ can be labeled as 'gluten-reduced'. However, the combination of lactobacilli with two fungal proteases from Aspergillus niger and A. oryzae has decreased the gluten concentration of wheat flour below $10 \mathrm{ppm}$ during fermentation (74).

Corroborating this, Gobbetti et al (72) observed that functional probiotics contribute to food tolerance through their array of enzymes. The probiotic VSL\#3 preparation containing Streptococcus thermophilus, L. plantarum, L. casei, L. delbrueckii spp. bulgaricus, Bifidobacterium breve, $B$. longum and $B$. infantis were the starters in baking. During fermentation, there was a marked degradation of wheat gluten (12). Upon the exposure of peptic-tryptic digest of VSL\#3 fermented dough to celiac jejunal biopsies, there was no increase in the infiltration of $\mathrm{CD}^{+}$intraepithelial lymphocytes (40). In the food industry, to improve the quality and other food parameters, microbial transglutaminases (mTG) are being used (75). The mTG formulated food could able to generate $\mathrm{T}$ cell reactive gluten epitopes by deamidation. Therefore, it is recommended not to use mTG in food formulations for celiacs. Based on these functions, it has been hypothesized that probiotics are distinctly involved in the dietetic management of $\mathrm{CD}$ (76).

\section{Mechanisms of action of probiotics in celiac disease}

Strengthening of intestinal epithelial barrier by probiotics. The intestinal epithelium is in constant interaction with the luminal contents, as well as the enteric microbiota. The major function of the intestinal epithelium is the maintenance of epithelial integrity. Generally, the intestinal mucous layer, antimicrobial peptides, secretory IgA-a dimer antibody, and the epithelial junction adhesion complex constitutes the defense system of the intestinal barrier (77). The disruption of this barrier facilitates the invasion of bacterial and food antigens into the submucosa, which further induces inflammatory responses, resulting in intestinal disorders, such as inflammatory bowel disease (IBD) (78). Furthermore, probiotic bacteria have been extensively studied for their beneficial role in the maintenance of the intestinal epithelial barrier. It has been reported that probiotics enhance the expression of genes that participate in tight junction signaling and possibly thereby reinforce the intestinal barrier integrity (79). Lactic acid 
bacteria ( $\mathrm{LAB}$ ) modulate the regulation of genes encoding adherence junction proteins in a T84 cell barrier model, which include E-cadherin and $\beta$-catenin. The incubation of intestinal cells with LAB differentially enhances the phosphorylation of adherence junction proteins and results in the formation of protein kinase $\mathrm{C}(\mathrm{PKC})$ isoforms, thereby positively regulating epithelial barrier function (80).

Studies have demonstrated that probiotics mediate the restoration of the impaired barrier function. In addition to the prevention of the enteropathogenic Escherichia coli (EPEC)-mediated disruption of the mucosal barrier, E. coli also restores the mucosal integrity in T84 and Caco- 2 cells. This effect was found to be mediated by the enhanced expression and redistribution of tight junction proteins of zonula occludens 2 (ZO-2) and $\mathrm{PKCl}$, resulting in the reconstruction of the TJ complex (81). Moreover, Lactobacillus casei isolates have been shown to sustain intestinal barrier function through similar mechanisms; they have also been shown to protect the epithelial barrier and to increase tight junction protein expression through the activation of the p38 and extracellular regulated kinase signaling pathways in in vivo and in vitro experiments (82). These probiotics enhance the strength of the intestinal epithelial barrier indirectly; thus, they may prove to be an effective therapy for CD (19).

Adhesion to intestinal mucosa by probiotics. The ability to adhere to the intestinal mucosa is considered as one of the main selection criteria for potential probiotics as it prolongs their persistence in the intestine and thus allows the probiotics to exert their beneficial effects (83). Several probiotic bacterial surface proteins have also been proven to promote mucous adhesion. The majority of the probiotic bacterial species are Gram-positive strains consisting of a thick peptidoglycan layer, polysaccharides such as teichoic acid and lipoteichoic acid, and various cell-surface proteins, including S-layer proteins. These typical cell surface structures are in direct contact with the environment and may function as adhesion factors, antigens, or receptors. In addition, they are also known to take part in various physiological functions (47). Based on the wide variation of molecular structures, lactobacilli exhibit various adhesive properties on mucin and mucin carbohydrate chains. Based on these observations, it has been suggested that Lactobacillus adapt to the constantly changing intestinal environment of the host, and further indicate that the adhesion factors of Lactobacillus, exhibiting specific binding affinities, allow them to selectively colonize inside the host while concurrently avoiding competition with other bacteria. This process is mediated by a variety of proteins, saccharide moieties and lipoteichoic acids (84). Lactobacillus reuteri produced mucus-binding protein (MUB) is the most studied example of mucus-targeting bacterial adhesins (85). The proteins accounting for the mucous adhesion phenotype of probiotics are mainly secreted and are surface-associated proteins, which are either anchored to the membrane through a lipid moiety or are embedded in the cell wall. Under certain conditions, these MUB play a crucial role in promoting gut colonization through the degradation of colonocytes extracellular matrix and or by establishing close contact with the epithelium (86). In an example, MapA (mucous adhesion-promoting protein) mediates binding of few LAB, such as L. reuteri and L.fermentum to mucus. L. plantarum, has also been shown to induce MUC2 and MUC3 mucins and inhibited the adherence of EPEC (83).

Furthermore, VSL\#3, a probiotic mixture, has been reported to enhance the expression of cell surface mucin genes (87). In addition, probiotics also lead to modifications in the intestinal mucins that prevent pathogen binding. Of note, the binding protein cleaved into an antimicrobial peptide confers an anti-pathogenic effect to the host, emphasizing the pleiotropic effect of probiotic surface proteins (88). Moreover, adhesion properties of gluten-hydrolyzing probiotics promise to improve the overall health of patients with CD (12).

Competitive exclusion of pathogens by probiotics. The concept of 'competitive exclusion' was first proposed by Greenberg (89), in which one particular bacterial species strongly competes for the receptor binding site in the intestinal tract with other species of bacteria. The mechanisms adapted by the bacterial species to exclude the competitive species vary and mainly include the establishment of a hostile environment, competing for available receptor sites, the production of antimicrobial compounds, and the competitive depletion of available nutrients. To elaborate further, in order to gain a competitive advantage, bacteria modify their environment unfavorable for the survival of their competitors by producing metabolites, such as organic acids (90). In general, probiotic cells are capable of inhibiting the attachment of pathogenic bacteria by means of steric hindrance at enterocyte pathogen receptors (88). Several studies have reported the effect of probiotics on the competitive exclusion of pathogens in vitro as well as in vivo. In the case of Lactobacillus rhamnosus, it was found to eliminate herpes simplex virus type I by activating macrophages (91). In addition, probiotics in the gut may also help to eradicate Helicobacter pylori, mitigating the frequency of epigastric pain, vomiting, nausea and diarrhea (92).

Effect of antimicrobial compounds produced from probiotics. The production of low molecular weight compounds $(<1,000 \mathrm{kDa})$, such as organic acids, and antibacterial substances called bacteriocins $(>1,000 \mathrm{kDa})$ are majorly responsible for the health benefits conferred by probiotics in the host (93). The organic acids produced by probiotics mainly lactic and acetic acids exert potent inhibitory effects on Gram-negative bacteria. These organic acids enter the bacterial cells in their un-dissociated form and in the cytoplasm they undergo dissociation. Furthermore, the accumulation of ionized form of organic acids and/or the lowering of the intracellular $\mathrm{pH}$ results in the death of target bacteria (83). A number of lactic acid bacteria produce bacteriocins, such as lactacin B (L. acidophilus), plantaricin (L. plantarum) and nisin (Lactococcus lactis) (94). Bacteriocins destruct the target cells by forming pores or inhibiting the cell wall synthesis. To consider, nisin forms a complex with lipid II and thereby inhibit the biosynthesis of cell wall (95). Bacteriocin production perhaps encourages the establishment and increases the prevalence of bacteriocin-producing strains, thus directly inhibiting pathogens in the gastrointestinal tract (12).

Furthermore, probiotics producing anti-metabolic substances inhibit the growth of fungi and other species of bacteria (96). Furthermore, the production of antifungal substances, such as 
Table I. List of commonly available commercial probiotics for human consumption $(110,111)$.

\begin{tabular}{|c|c|c|c|}
\hline Microorganism & Company & Microorganism & Company \\
\hline $\begin{array}{l}\text { Bifidobacterium adolescentis } \\
\text { ATCC } 15703\end{array}$ & Chr. Hansen & $\begin{array}{l}\text { Bacillus cereus strain IP } 5832 \\
\text { (ATCC 14893) }\end{array}$ & $\begin{array}{l}\text { Marion Merrell Dow } \\
\text { Laboratories }\end{array}$ \\
\hline Bifidobacterium animalis Bb-12 & Chr. Hansen & Bacillus subtilis & Tendiphar Corporation \\
\hline Bifidobacterium essencis & Danone $^{\circledR}$ (Activia) & B. subtilis & $\begin{array}{l}\text { Bidiphar-BinhDinh } \\
\text { Pharmaceutical }\end{array}$ \\
\hline Bifidobacterium infantis & Yakult Danone $^{\circledR}$ & B. subtilis 2335 and B. licheniformis 2336 & Biofarm \\
\hline Bifidobacterium lactis & DSM & B. subtilis and Lactobacillus acidophilus & IVAC \\
\hline Bacillus lactis DR10 & Danisco $\left(\right.$ Howaru $\left.{ }^{\mathrm{TM}}\right)$ & B.pumilus & Biophar Company \\
\hline Lactobacillus acidophilus & Chr. Hansen & B. cereus strain GM & Geyer Medicamentos S. \\
\hline LA-1/LA-5 & Rhodia & & \\
\hline NCFM & Nebraska Cultures & & \\
\hline DDS-1 & Snow Brand Milk & & \\
\hline SBT-2062 & Products & & \\
\hline Lactobacillus casei & $\begin{array}{l}\text { Yakult }\left(\text { Yakult }^{\circledR}\right), \\
\text { Danone }^{\circledR}\end{array}$ & B. polyfermenticus SCD & Binex Co., Ltd. \\
\hline Lactobacillus fermentum $\mathrm{RC}-14$ & Urex Biotech & $\begin{array}{l}\text { B. subtilis strain } \mathrm{RO} 179 \\
\text { Enterococcus faecium }\end{array}$ & $\begin{array}{l}\text { Hanmi Pharmaceutical } \\
\text { Co., Ltd. }\end{array}$ \\
\hline Lactobacillus lactis L1A & Essum AB & $\begin{array}{l}\text { B. subtilis, B. polymyxa, } \\
\text { B.pumilus } \\
\text { B. laterosporus }\end{array}$ & Nature's First Law \\
\hline Lactobacillus rhamnosus & Valio & B. subtilis & Pasteur Institute of Ho \\
\hline GG & Urex Biotech & & Chi Minh City \\
\hline GR-1 & Essum AB & & \\
\hline LB21 & Probi AB & & \\
\hline 271 & & & \\
\hline $\begin{array}{l}\text { Lactobacillus plantarum } \\
\text { 299v Lp01 }\end{array}$ & Probi AB & B. cereus & $\begin{array}{l}\text { Mekophar, } \\
\text { Pharmaceutical Factory }\end{array}$ \\
\hline
\end{tabular}

benzoic acid, methylhydantoin, mevalonolactone and short-chain fatty acids by Lactobacillus spp. are quite evident (97). Another study reported the production of proteinaceous compounds exhibiting antifungal properties by Lactobacillus coryniformis (98). In addition, Dal Bello et al (99) identified and chemically characterized the 4 antifungal substances produced by L. plantarum FST 1.7, including lactic acid, phenyl lactic acid and 2 cyclic dipeptides, [cyclo(L-Leu-L-Pro) and cyclo(L-Phe-L-Pro)]. A similar study reported the production of the antifungal cyclic dipeptides, cyclo (L-Phe-L-Pro) and cyclo (L-Phe-traps-4-OH-L-Pro), by lactic acid bacteria, which inhibited the growth of food borne fungi (100).

Immunomodulatory effect of probiotics. Probiotics interact with intestinal epithelial cells, macrophages, lymphocytes and dendritic cells (101). In the adaptive immune response, $\mathrm{B}$ and $\mathrm{T}$ cells specific for pathogens play an important role, while the innate immune system responds to pathogen-associated molecular patterns (PAMPs) which are shared by the majority of pathogens. The pattern recognition receptors (PRP) that bind to PAMP trigger primary immune response to pathogens (47). Furthermore, Toll-like receptors (TLRs) are transmembrane proteins that are expressed on various immune, as well as non-immune cells. In humans, there are 11 classes of TLRs that have been identified thus far. Amongst these, TLR1, TLR2, TLR4, TLR5, TLR6 and TLR10 are associated with the outer membrane and primarily respond to bacterial surface-associated PAMPs. On the other hand, TLR3, TLR7, TLR8 and TLR9 are found on the surface of endosomes, and they respond primarily to nucleic acid-based PAMPs from viruses and other bacteria (101). In addition, the TLR-mediated signaling has been shown to regulate the maturation of dendritic cells, upregulating various maturation markers such as CD80, CD83 and CD86, as well as CCR7 chemokine receptor. Moreover, it has been observed that following activation by commensal and probiotic microorganisms, dendritic cells initiate an appropriate response, such as the differentiation of $\mathrm{Th}_{0}$ to $\mathrm{T}_{\text {reg }}$, which exhibit an inhibitory effect on the $\mathrm{Th}_{1}, \mathrm{Th}_{2}$ and $\mathrm{Th}_{17}$ inflammatory response (102).

Probiotics reduce intestinal inflammation via the downregulation of TLR expression. The secretary metabolites from probiotics prevent the entry of TNF- $\alpha$ into blood mononuclear cells and also arrest NF- $\kappa \mathrm{B}$ signaling in enterocytes (101). Furthermore, TLRs recognize peptidoglycan, a major component of Gram-positive bacteria. Several studies have demonstrated the necessity of TLRs for lactobacilli to exert their immunomodulatory effects. It has been shown that the cell wall components of lactobacilli mainly diacylated membrane anchors of lipoproteins and lipoteichoic acids take part in signaling upon concurrent binding to TLR2 and TLR6. The activation of 
TLR2 enhances the production of cytokines and also increases transepithelial resistance to invading pathogens $(12,103)$. This evidence supports immunomodulatory functions of probiotic bacteria in their host and reduce the $\mathrm{CD}$ with managing the inflammation inducing transmembrane signals $(19,104)$.

Safety and efficacy of probiotics for human use. It is mandatory that any given probiotic strain should not be at any significant risk with regard to transferable antibiotic resistance (105). Furthermore, if any strain is under evaluation belonging to a particular species, it needs to be examined for toxin production and/or hemolytic activity (106). The assessment of a lack of infectivity by a probiotic strain in immune compromised individuals would be an additional advantage to human use (107). The outcome of efficacy studies on probiotics are required to be proven significantly with benefits in human trials, such as an improvement in conditions, symptoms, signs, wellbeing/quality of life, a reduced risk of disease or longer time to next occurrence or faster recovery from illness $(19,104)$. Each of the parameters should have a proven association with probiotics and may be helpful for CD therapy (108).

\section{Commonly available commercial probiotics}

The indigenous microbiota of infants is dominated by bifidobacteria, which are recognized shortly after birth. Their proliferation is stimulated by the glycoprotein components of $\mathrm{k}$-casein in human colostrum and, to a lesser extent, human milk. The extent of bifidobacterial population decreases with the increasing age of the human subject and eventually becomes the third most abundant genus (accounting for approximately $25 \%$ of the total adult gut microbiota) after the genera Bacteroides and Eubacterium (109). The commonly available probiotics are from the strains belonging to the genera, Lactobacillus, Streptococcus, Bifidobacterium and Bacillus spp. The commercially available probiotic products in the market $(110,111)$ are listed in Table I. Bifidobacteria are microorganisms of paramount importance in the active and complex ecosystem of the intestinal tract of humans and human gastrointestinal and genitourinary tracts, the exact ratio of which is determined mainly by age and diet (19).

Bacillus spp. have been used as a probiotic for at least 50 years in an Italian product commercialized as Enterogermina ${ }^{\circledR}$ ( $2 \mathrm{X} 10^{9}$ spores). Among this group, some species that have been evaluated for their probiotic potential, which include Bacillus subtilis, Bacillus clausii, Bacillus cereus, Bacillus coagulans and Bacillus licheniformis (112). Currently, in the market, probiotic products containing GRAS isolates of Bacillus are increasingly available, including Bacillus subtilis, Bacillus cereus, Bacillus licheniformis, Bacillus pumilus, Bacillus clausii and Bacillus coagulans (111). The members of Bacillus have been proven to form dormant forms as endospores, a protective mechanism to overcome the unfavorable conditions, such as nutrient deprivation and other factors of environmental stress. The tough coat of endospores confers resistance to high temperatures, low $\mathrm{pH}$ and low moisture conditions $(67,68,113)$. Taking into account the advantage of this property, unlike Lactobacillus, Bifidobacteria and other commonly used probiotic lactic acid bacteria, Bacillus probiotics can be used in the form of spores, which has an indefinite shelf life and does not require refrigeration (114). Furthermore, studies have demonstrated the potential probiotic attributes of the Bacillus spp. and their efficacy in gastrointestinal disorders $(112,113)$. Consequently, GRAS isolates of Bacillus spp. have attracted the attention of the probiotic industry, having more advantages over conventional probiotic lactic acid bacteria.

Other probiotic bacteria include Leuconostoc mesenteroides, Leuconostoc lactis, Streptococcus thermophilus, and Pediococcus spp. (115). Among the probiotic yeasts, the most common genus, Saccharomyces cerevisiae has been used as a potential probiotic. The potential probiotic effect of $S$. cerevisiae and S. cerevisiae var. boulardii has been demonstrated since they are able to tolerate low $\mathrm{pH}$ and bile and protect against bacterial infections through the reduction of the intestinal pro-inflammatory response (116) and have been used worldwide as a therapeutic agent for diarrhea and other gastrointestinal disturbances caused by the administration of antimicrobial agents (117). Although lactic acid bacteria are beneficial in alleviating or managing various health issues, in recent times, these bacteria are used in alleviating a high intolerance of gluten allergy leading to CD $(12,19,104)$; therefore, they have become a food of choice by patients with CD.

\section{Conclusion}

Current probiotic research aims at the use of the normal, healthy gut microbiota as a therapy for $\mathrm{CD}$ and their implications on human health. From all these aspects, probiotics are generally safe and cost-effective compared to the drugs available in the market. Bifidobacterium spp. and Lactobacilli spp. are the promising agents for probiotic therapy for patients with $\mathrm{CD}$. Further studies should emphasize on microbiota characterization with potential benefits to gut health of patients with CD. The molecular mechanisms of probiotic action are in a tranquil state and require to be characterized. The future metabolomic approach would provide insight into the knowledge of the mechanisms of the microbiota for CD therapy.

\section{Acknowledgements}

The authors sincerely acknowledge the support rendered by Davangere University, Davangere, Karnataka, India

\section{Funding}

No funding was received.

\section{Availability of data and materials}

Not applicable.

\section{Authors' contributions}

DG conceived the study, drafted the manuscript, and was also involved in editing, reviewing and revising the manuscript, and also communicated the manuscript to the journal. AR was involved in the conception of the study, as well as in the processing of the data acquired for this review, the drafting of the manuscript and processing of the figure. AR was also 
involved in the study design and editing of the manuscript. Both authors have read and approved the final manuscript.

\section{Ethics approval and consent to participate}

Not applicable.

\section{Patient consent for publication}

Not applicable.

\section{Competing interests}

The authors declare that they have no competing interests.

\section{References}

1. Losowsky MS: A history of coeliac disease. Dig Dis 26: 112-120, 2008.

2. Dowd B and Walker-Smith J: Samuel Gee, Aretaeus, and the coeliac affection. BMJ 2: 45-47, 1974.

3. Fasano A: Surprises from celiac disease. Sci Am 301: 54-61, 2009.

4. Dubé C, Rostom A, Sy R, Cranney A, Saloojee N, Garritty C, Sampson M, Zhang L, Yazdi F, Mamaladze V, et al: The prevalence of celiac disease in average-risk and at-risk Western European populations: A systematic review. Gastroenterology 128 (Suppl 1): S57-S67, 2005.

5. Barada K, Bitar A, Mokadem MA, Hashash JG and Green P: Celiac disease in Middle Eastern and North African countries: A new burden? World J Gastroenterol 16: 1449-1457, 2010.

6. Yadav P, Das P, Mirdha BR, Gupta SD, Bhatnagar S, Pandey RM and Makharia GK: Current spectrum of malabsorption syndrome in adults in India. Indian J Gastroenterol 30: 22-28, 2011.

7. Fasano A, Berti I, Gerarduzzi T, Not T, Colletti RB, Drago S, Elitsur Y, Green PH, Guandalini S, Hill ID, et al: Prevalence of celiac disease in at-risk and not-at-risk groups in the United States: A large multicenter study. Arch Intern Med 163: 286-292, 2003.

8. Mohindra S, Yachha SK, Srivastava A, Krishnani N, Aggarwal R, Ghoshal UC, Prasad KK and Naik SR: Coeliac disease in Indian children: Assessment of clinical, nutritional and pathologic characteristics. J Health Popul Nutr 19: 204-208, 2001.

9. Sollid LM: Molecular basis of celiac disease. Annu Rev Immunol 18: 53-81, 2000.

10. Korponay-Szabó IR, Halttunen T, Szalai Z, Laurila K, Király R, Kovács JB, Fésüs L and Mäki M: In vivo targeting of intestinal and extraintestinal transglutaminase 2 by coeliac autoantibodies Gut 53: 641-648, 2004.

11. Ivarsson A, Hernell O, Stenlund $\mathrm{H}$ and Persson LA: Breast-feeding protects against celiac disease. Am J Clin Nutr 75: 914-921, 2002.

12. Chander AM, Yadav H, Jain S, Bhadada SK and Dhawan DK: Cross-talk between gluten, intestinal microbiota and intestinal mucosa in celiac disease: Recent advances and basis of autoimmunity. Front Microbiol 9: 2597, 2018.

13. Rastogi A, Bhadada SK, Bhansali A, Kochhar R and Santosh R: Celiac disease: A missed cause of metabolic bone disease. Indian J Endocrinol Metab 16: 780-785, 2012.

14. Howard MR, Turnbull AJ, Morley P, Hollier P, Webb R and Clarke A: A prospective study of the prevalence of undiagnosed coeliac disease in laboratory defined iron and folate deficiency. J Clin Pathol 55: 754-757, 2002.

15. Rostom A, Murray JA and Kagnoff MF: American Gastroenterological Association (AGA) Institute technical review on the diagnosis and management of celiac disease. Gastroenterology 131: 1981-2002, 2006.

16. Annibale B, Lahner E, Chistolini A, Gailucci C, Di Giulio E, Capurso G, Luana O, Monarca B and Delle Fave G: Endoscopic evaluation of the upper gastrointestinal tract is worthwhile in premenopausal women with iron deficiency anaemia irrespective of menstrual flow. Scand J Gastroenterol 38: 239-245, 2003.

17. Ludvigsson JF, Osby U, Ekbom A and Montgomery SM: Coeliac disease and risk of schizophrenia and other psychosis: A general population cohort study. Scand J Gastroenterol 42: 179-185, 2007

18. Gayathri D and Rashmi BS: Development of celiac disease; pathogenesis and strategies to control: A molecular approach. J Nutr Food Sci 4: 310, 2014.
19. Coqueiro AY, Bonvini A, Tirapegui J and Rogero MM: Probiotics supplementation as an alternative method for celiac disease treatment. Int J Probiotics Prebiotics 12: 23-32, 2017.

20. Högberg L, Fälth-Magnusson K, Grodzinsky E and Stenhammar L: Familial prevalence of coeliac disease: A twenty-year follow-up study. Scand J Gastroenterol 38: 61-65, 2003.

21. Hill ID: Management of celiac disease in childhood and adolescence: Unique challenges and strategies. Curr Treat Options Gastroenterol 9: 399-408, 2006.

22. Ludvigsson JF, Fälth-Magnusson K and Ludvigsson J: Tissue transglutaminase auto-antibodies in cord blood from children to become celiacs. Scand J Gastroenterol 36: 1279-1283, 2001.

23. Sollid LM, Markussen G, Ek J, Gjerde H, Vartdal F and Thorsby E: Evidence for a primary association of celiac disease to a particular HLA-DQ alpha/beta heterodimer. J Exp Med 169: 345-350, 1989.

24. Kaur G, Sarkar N, Bhatnagar S, Kumar S, Rapthap CC, Bhan MK and Mehra NK: Pediatric celiac disease in India is associated with multiple DR3-DQ2 haplotypes. Hum Immunol 63: 677-682, 2002.

25. Megiorni F and Pizzuti A: HLA-DQA1 and HLA-DQB1 in Celiac disease predisposition: Practical implications of the HLA molecular typing. J Biomed Sci 19: 88, 2012.

26. van de Wal Y, Kooy YM, van Veelen P, Vader W, August SA, Drijfhout JW, Peña SA and Koning F: Glutenin is involved in the gluten-driven mucosal T cell response. Eur J Immunol 29: 3133-3139, 1999.

27. Molberg O,Kett K, Scott H, Thorsby E, Sollid LM and Lundin KE: Gliadin specific, HLA DQ2-restricted T cells are commonly found in small intestinal biopsies from coeliac disease patients, but not from controls. Scand J Immunol 46: 103-109, 1997.

28. Arentz-Hansen H, Körner R, Molberg O, Quarsten H, Vader W, Kooy YM, Lundin KE, Koning F, Roepstorff P, Sollid LM, et al: The intestinal $\mathrm{T}$ cell response to alpha-gliadin in adult celiac disease is focused on a single deamidated glutamine targeted by tissue transglutaminase. J Exp Med 191: 603-612, 2000.

29. Visser J, Rozing J, Sapone A, Lammers K and Fasano A: Tight junctions, intestinal permeability, and autoimmunity: Celiac disease and type 1 diabetes paradigms. Ann N Y Acad Sci 1165: 195-205, 2009.

30. Ráki M, Schjetne KW, Stamnaes J, Molberg Ø, Jahnsen FL, Issekutz TB, Bogen B and Sollid LM: Surface expression of transglutaminase 2 by dendritic cells and its potential role for uptake and presentation of gluten peptides to T cells. Scand J Immunol 65: 213-220, 2007.

31. Manavalan JS, Hernandez L, Shah JG, Konikkara J, Naiyer AJ, Lee AR, Ciaccio E, Minaya MT, Green PH and Bhagat G: Serum cytokine elevations in celiac disease: Association with disease presentation. Hum Immunol 71: 50-57, 2010.

32. Xu H, Feely SL, Wang X, Liu DX, Borda JT, Dufour J, Li W, Aye PP, Doxiadis GG, Khosla C, et al: Gluten-sensitive enteropathy coincides with decreased capability of intestinal $\mathrm{T}$ cells to secrete IL-17 and IL-22 in a macaque model for celiac disease. Clin Immunol 147: 40-49, 2013.

33. Husby S, Koletzko S, Korponay-Szabó IR, Mearin ML, Phillips A, Shamir R, Troncone R, Giersiepen K, Branski D, Catassi C, et al; ESPGHAN Working Group on Coeliac Disease Diagnosis; ESPGHAN Gastroenterology Committee; European Society for Pediatric Gastroenterology, Hepatology, and Nutrition: European Society for Pediatric Gastroenterology, Hepatology, and Nutrition guidelines for the diagnosis of coeliac disease. J Pediatr Gastroenterol Nutr 54: 136-160, 2012.

34. Fasano A, Araya M, Bhatnagar S, Cameron D, Catassi C, Dirks M, Mearin ML, Ortigosa L and Phillips A; Celiac Disease Working Group, FISPGHAN: Federation of International Societies of Pediatric Gastroenterology, Hepatology, and Nutrition consensus report on celiac disease. J Pediatr Gastroenterol Nutr 47: 214-219, 2008.

35. Ciacci C, Maiuri L, Russo I, Tortora R, Bucci C, Cappello C, Santonicola A, Luciani A, Passananti V and Iovino P: Efficacy of budesonide therapy in the early phase of treatment of adult coeliac disease patients with malabsorption: An in vivo/in vitro pilot study. Clin Exp Pharmacol Physiol 36: 1170-1176, 2009.

36. Liang L, Pinier M, Leroux JC and Subirade M: Interaction of alpha-gliadin with poly(HEMA-co-SS): Structural characterization and biological implication. Biopolymers 91: 169-178, 2009.

37. Dieterich W, Trapp D, Esslinger B, Leidenberger M, Piper J, Hahn E and Schuppan D: Autoantibodies of patients with coeliac disease are insufficient to block tissue transglutaminase activity. Gut 52: 1562-1566, 2003. 
38. Goerres MS, Meijer JW, Wahab PJ, Kerckhaert JA, Groenen PJ, Van Krieken JH and Mulder CJ: Azathioprine and prednisone combination therapy in refractory coeliac disease. Aliment Pharmacol Ther 18: 487-494, 2003.

39. Pinier M, Fuhrmann G, Galipeau HJ, Rivard N, Murray JA, David CS, Drasarova H, Tuckova L, Leroux JC and Verdu EF: The copolymer P(HEMA-co-SS) binds gluten and reduces immune response in gluten-sensitized mice and human tissues. Gastroenterology 142: 316-25.e1, 12, 2012.

40. De Angelis M, Cassone A, Rizzello CG, Gagliardi F, Minervini F, Calasso M, Di Cagno R, Francavilla R and Gobbetti M: Mechanism of degradation of immunogenic gluten epitopes from Triticum turgidum L. var. durum by sourdough lactobacilli and fungal proteases. Appl Environ Microbiol 76: 508-518, 2010.

41. Gass J, Ehren J, Strohmeier G, Isaacs I and Khosla C: Fermentation, purification, formulation, and pharmacological evaluation of a prolyl endopeptidase from Myxococcus xanthus: Implications for Celiac Sprue therapy. Biotechnol Bioeng 92: 674-684, 2005.

42. Hallert C, Grant C, Grehn S, Grännö C, Hultén S, Midhagen G, Ström M, Svensson H and Valdimarsson T: Evidence of poor vitamin status in coeliac patients on a gluten-free diet for 10 years. Aliment Pharmacol Ther 16: 1333-1339, 2002.

43. Asha and Gayathri D: Synergistic impact of Lactobacillus fermentum, Lactobacillus plantarum and vincristine on 1,2-dimethylhydrazine-induced colorectal carcinogenesis in mice. Exp Ther Med 3: 1049-1054, 2012.

44. Gayathri D, Asha and Devaraja TN: Lactobacillus sp. as probiotics for human health with special emphasis on colorectal cancer. Indian J Sci Technol 4: 1008-1014, 2011.

45. Quigley EMM: Gut bacteria in health and disease. Gastroenterol Hepatol (N Y) 9: 560-569, 2013.

46. Patel RM and Lin PW: Developmental biology of gut-probiotic interaction. Gut Microbes 1: 186-195, 2010.

47. Lebeer S, Vanderleyden J and De Keersmaecker SC: Host interactions of probiotic bacterial surface molecules: Comparison with commensals and pathogens. Nat Rev Microbiol 8: 171-184, 2010.

48. Pagnini C, Saeed R, Bamias G, Arseneau KO, Pizarro TT and Cominelli F: Probiotics promote gut health through stimulation of epithelial innate immunity. Proc Natl Acad Sci USA 107: 454-459, 2010

49. Corr SC, Li Y, Riedel CU, O'Toole PW, Hill C and Gahan CG: Bacteriocin production as a mechanism for the antiinfective activity of Lactobacillus salivarius UCC118. Proc Natl Acad Sci USA 104: 7617-7621, 2007.

50. Metchnikoff E: The nature of man. Studies in optimistic philosophy. William Heinemann, London, 1908.

51. Fuller R: Probiotics in man and animals. J Appl Bacteriol 66: 365-378, 1989

52. Havenaar R, Brink T and Huis in't Veld JHJ: Selection of Strains for Probiotic Use. In: Probiotics: The Scientific Basis. Fuller R (ed). Chapman \& Hall, London, pp151-170, 1992

53. Salminen S, Ouwehand A, Benno Y and Lee YK: Probiotics: How should they be defined. Trends Food Sci Technol 10 107-110, 1999.

54. Khatri I, Sharma S, Ramya TNC and Subramanian S: Complete genomes of Bacillus coagulans S-lac and Bacillus subtilis TO-A JPC, two phylogenetically distinct probiotics. PLoS One 11: e0156745, 2016

55. Isolauri E, Salminen S and Ouwehand AC: Microbial-gut interactions in health and diseasein infective diarrhoea and inflammatory bowel diseases. J Gastroenterol Hepatol 15: 489-493, 2000

56. Loponen J: Prolamin degradation in sourdoughs(unpublished $\mathrm{PhD}$ thesis). University of Helsinki, 2006.

57. Piper JL, Gray GM and Khosla C: Effect of prolyl endopeptidase on digestive-resistant gliadin peptides in vivo. J Pharmacol Exp Ther 311: 213-219, 2004.

58. Hausch F, Shan L, Santiago NA, Gray GM and Khosla C: Intestinal digestive resistance of immunodominant gliadin peptides. Am J Physiol Gastrointest Liver Physiol 283: G996-G1003, 2002.

59. Tye-Din JA, Anderson RP, Ffrench RA, Brown GJ, Hodsman P, Siegel M, Botwick W and Shreeniwas R: The effects of ALV003 pre-digestion of gluten on immune response and symptoms in celiac disease in vivo. Clin Immunol 134: 289-295, 2010.

60. Shan L, Marti T, Sollid LM, Gray GM and Khosla C: Comparative biochemical analysis of three bacterial prolyl endopeptidases: Implications for coeliac sprue. Biochem J 383: 311-318, 2004

61. Pyle GG, Paaso B, Anderson BE, Allen DD, Marti T, Li Q Siegel M, Khosla C and Gray GM: Effect of pretreatment of food gluten with prolyl endopeptidase on gluten-induced malabsorption in celiac sprue. Clin Gastroenterol Hepatol 3: 687-694, 2005.
62. Chen YS, Christensen JE, Broadbent JR and Steele JL: Identification and characterization of Lactobacillus helveticus PepO2, an endopeptidase with post-proline specificity. Appl Environ Microbiol 69: 1276-1282, 2003.

63. Rashmi BS and Gayathri D: Draft genome sequence of gluten hydrolysing bacterium Bacillus subtilis GS 188, Isolated from Wheat Sourdough. Genome Announc 5: e00952, 2017.

64. Rashmi BS and Gayathri D: Molecular characterization of gluten hydrolysing Bacillus sp. and their efficacy and biotherapeutic potential as probiotics using Caco-2 cell line. J Appl Microbiol 123: 759-772, 2017.

65. Stepniak D, Spaenij-Dekking L, Mitea C, Moester M, de Ru A, Baak-Pablo R, van Veelen P, Edens L and Koning F: Highly efficient gluten degradation with a newly identified prolyl endoprotease: Implications for celiac disease. Am J Physiol Gastrointest Liver Physiol 291: G621-G629, 2006.

66. Edens L, Dekker P, van der Hoeven R, Deen F, de Roos A and Floris R: Extracellular prolyl endoprotease from Aspergillus niger and its use in the debittering of protein hydrolysates. J Agric Food Chem 53: 7950-7957, 2005.

67. Di Cagno R, De Angelis M, Lavermicocca P, De Vincenzi M, Giovannini C, Faccia M and Gobbetti M: Proteolysis by sourdough lactic acid bacteria: Effects on wheat flour protein fractions and gliadin peptides involved in human cereal intolerance. Appl Environ Microbiol 68: 623-633, 2002.

68. Gobbetti M, Cagno RD and De Angelis M: Functional microorganisms for functional food quality. Crit Rev Food Sci Nutr 50: 716-727, 2010

69. di Cagno R, de Angelis M, Alfonsi G, de Vincenzi M, Silano M, Vincentini $\mathrm{O}$ and Gobbetti M: Pasta made from durum wheat semolina fermented with selected lactobacilli as a tool for a potential decrease of the gluten intolerance. J Agric Food Chem 53: 4393-4402, 2005

70. Rizzello CG, De Angelis M, Di Cagno R, Camarca A, Silano M, Losito I, De Vincenzi M, De Bari MD, Palmisano F, Maurano F, et al: Highly efficient gluten degradation by lactobacilli and fungal proteases during food processing: New perspectives for celiac disease. Appl Environ Microbiol 73: 4499-4507, 2007.

71. Dekking EHA, Veelen PAV, de Ru A, Kooy-Winkelaar EMC and Groneveld T: Microbial transglutaminases generate $\mathrm{T}$ cell stimulatory epitopes involved in celiac disease. J Cereal Sci 47: 339-346, 2008

72. de Sousa Moraes LF, Grzeskowiak LM, de Sales Teixeira TF and Gouveia Peluzio MC: Intestinal microbiota and probiotics in celiac disease. Clin Microbiol Rev 27: 482-489, 2014.

73. Ohland CL and Macnaughton WK: Probiotic bacteria and intestinal epithelial barrier function. Am J Physiol Gastrointest Liver Physiol 298: G807-G819, 2010.

74. Sartor RB: Mechanisms of disease: Pathogenesis of Crohn's disease and ulcerative colitis. Nat Clin Pract Gastroenterol Hepatol 3: 390-407, 2006.

75. Anderson RC, Cookson AL, McNabb WC, Park Z, McCann MJ, Kelly WJ and Roy NC: Lactobacillus plantarum MB452 enhances the function of the intestinal barrier by increasing the expression 1. Probiotics. Best Pract Res Clin Gastroenterol 18: 299-313, 2004

76. O'Shea EF, Cotter PD, Stanton C, Ross RP and Hill C: Production of bioactive substances by intestinal bacteria as a basis for explaining probiotic mechanisms: Bacteriocins and conjugated linoleic acid. Int J Food Microbiol 152: 189-205, 2012.

77. Thomas CM and Versalovic J: Probiotics-host communication: Modulation of signaling pathways in the intestine. Gut Microbes 1: $148-163,2010$.

78. Boirivant $\mathrm{M}$ and Strober $\mathrm{W}$ : The mechanism of action of probiotics. Curr Opin Gastroenterol 23: 679-692, 2007.

79. Gionchetti P, Rizzello F, Venturi A and Campieri M: Probiotics evels of genes involved in tight junction formation. BMC Microbiol 10: 316,2010

80. Hummel S, Veltman K, Cichon C, Sonnenborn U and Schmidt MA: Differential targeting of the E-Cadherin/ $\beta$-Catenin complex by gram-positive probiotic lactobacilli improves epithelial barrier function. Appl Environ Microbiol 78: 1140-1147, 2012.

81. Zyrek AA, Cichon C, Helms S, Enders C, Sonnenborn U and Schmidt MA: Molecular mechanisms underlying the probiotic effects of Escherichia coli Nissle 1917 involve ZO-2 and PKCzeta redistribution resulting in tight junction and epithelial barrier repair. Cell Microbiol 9: 804-816, 2007.

82. Dai C, Zhao DH and Jiang M: VSL\#3 probiotics regulate the intestinal epithelial barrier in vivo and in vitro via the p38 and ERK signaling pathways. Int J Mol Med 29: 202-208, 2012. 
83. Ouwehand AC, Salminen S, Tölkkö S, Roberts P, Ovaska J and Salminen E: Resected human colonic tissue: New model for characterizing adhesion of lactic acid bacteria. Clin Diagn Lab Immunol 9: 184-186, 2002.

84. Vélez MP, De Keersmaecker SC and Vanderleyden J: Adherence factors of Lactobacillus in the human gastrointestinal tract. FEMS Microbiol Lett 276: 140-148, 2007.

85. Buck BL, Altermann E, Svingerud T and Klaenhammer TR: Functional analysis of putative adhesion factors in Lactobacillus acidophilus NCFM. Appl Environ Microbiol 71: 8344-8351, 2005.

86. Sánchez B, Urdaci MC and Margolles A: Extracellular proteins secreted by probiotic bacteria as mediators of effects that promote mucosa-bacteria interactions. Microbiology 156: 3232-3242, 2010.

87. Juntunen M, Kirjavainen PV, Ouwehand AC, Salminen SJ and Isolauri E: Adherence of probiotic bacteria to human intestinal mucus in healthy infants and during rotavirus infection. Clin Diagn Lab Immunol 8: 293-296, 2001.

88. Coconnier MH, Bernet MF, Chauvière G and Servin AL: Adhering heat-killed human Lactobacillus acidophilus, strain LB, inhibits the process of pathogenicity of diarrhoeagenic bacteria in cultured human intestinal cells. J Diarrhoeal Dis Res 11: 235-242, 1993.

89. Greenberg B: Salmonella suppression by known populations of bacteria in flies. J Bacteriol 99: 629-635, 1969.

90. Schiffrin EJ and Blum S: Interactions between the microbiota and the intestinal mucosa. Eur J Clin Nutr 56 (Suppl 3): S60-S64, 2002.

91. Khani S, Motamedifar M, Golmoghaddam H, Hosseini HM and Hashemizadeh Z: In vitro study of the effect of a probiotic bacterium Lactobacillus rhamnosus against herpes simplex virus type 1. Braz J Infect Dis 16: 129-135, 2012.

92. Ahmad K, Fatemeh F, Mehri N and Maryam S: Probiotics for the treatment of pediatric Helicobacter pylori infection: A randomized double blind clinical trial. Iran J Pediatr 23: 79-84, 2013.

93. De Keersmaecker SC, Verhoeven TL, Desair J, Marchal K, Vanderleyden J and Nagy I: Strong antimicrobial activity of Lactobacillus rhamnosus GG against Salmonella typhimurium is due to accumulation of lactic acid. FEMS Microbiol Lett 259: 89-96, 2006.

94. Hassan M, Kjos M, Nes IF, Diep DB and Lotfipour F: Natural antimicrobial peptides from bacteria: Characteristics and potential applications to fight against antibiotic resistance. J Appl Microbiol 113: 723-736, 2012.

95. Bierbaum G and Sahl HG: Lantibiotics: Mode of action, biosynthesis and bioengineering. Curr Pharm Biotechnol 10: 2-18, 2009.

96. Coloretti F, Carri S, Armaforte E, Chiavari C, Grazia L and Zambonelli C: Antifungal activity of lactobacilli isolated from salami. FEMS Microbiol Lett 271: 245-250, 2007.

97. Prema P, Smila D, Palavesam A and Immanuel G: Production and characterization of an antifungal compound (3-phenyllactic acid) produced by Lactobacillus plantarum strain. Food Bioprocess Technol 3: 379-386, 2008.

98. Magnusson J and Schnürer J: Lactobacillus coryniformis subsp coryniformis strain $\mathrm{Si} 3$ produces a broad-spectrum proteinaceous antifungal compound. Appl Environ Microbiol 67: 1-5, 2001.

99. Dal Bello F, Clarke CI, Ryan LAM, Ulmer H, Schober TJ, Ström K, Sjögren J, van Sinderen D, Schnürer J and Arendt EK: Improvement of the quality and shelf life of wheat bread by fermentation with the antifungal strain Lactobacillus plantarum FST 1.7. J Cereal Sci 45: 309-318, 2007.
100. Ström K, Sjögren J, Broberg A and Schnürer J: Lactobacillus plantarum MiLAB 393 produces the antifungal cyclic dipeptides cyclo(L-Phe-L-Pro) and cyclo(L-Phe-trans-4-OH-L-Pro) and 3-phenyllactic acid. Appl Environ Microbiol 68: 4322-4327, 2002.

101. Gómez-Llorente C, Muñoz S and Gil A: Role of Toll-like receptors in the development of immunotolerance mediated by probiotics. Proc Nutr Soc 69: 381-389, 2010.

102. Wells JM: Immunomodulatory mechanisms of lactobacilli. Microb Cell Fact 10 (Suppl 1): S17, 2011.

103. Vizoso Pinto MG, Rodriguez Gómez M, Seifert S, Watzl B, Holzapfel WH and Franz CM: Lactobacilli stimulate the innate immune response and modulate the TLR expression of HT29 intestinal epithelial cells in vitro. Int J Food Microbiol 133: 86-93, 2009.

104. D'Angelo C, Reale M and Costantini E: Microbiota and Lnd HIV infection. Nutrients 9: 615, 2017.

105. Sharma P, Tomar SK, Goswami P, Sangwan SR and Singh R: Antibiotic resistance among commercially available probiotics. Food Res Int 57: 176-195, 2014.

106. Sorokulova IB, Pinchuk IV, Denayrolles M, Osipova IG, Huang JM, Cutting SM and Urdaci MC: The safety of two Bacillus probiotic strains for human use. Dig Dis Sci 53: 954-963, 2008.

107. Sanders ME, Akkermans LM, Haller D, Hammerman C, Heimbach J, Hörmannsperger G, Huys G, Levy DD, Lutgendorff F, Mack D, et al: Safety assessment of probiotics for human use. Gut Microbes 1: 164-185, 2010.

108. McFarland LV and Dublin S: Meta-analysis of probiotics for the treatment of irritable bowel syndrome. World J Gastroenterol 14 2650-2661, 2008

109. Finegold SM, Sutter VL and Mathisen GE: Normal indigenous intestinal flora. In: Human Intestinal Microflora in Health and Disease. Hentiges DJ (ed). Academic Press, New York, NY, 1983.

110. Didari T, Solki S, Mozaffari S, Nikfar S and Abdollahi M: A systematic review of the safety of probiotics. Expert Opin Drug Saf 13: 227-239, 2014

111. Hong HA, Duc H and Cutting SM: The use of bacterial spore formers as probiotics. FEMS Microbiol Rev 29: 813-835, 2005.

112. Cutting SM: Bacillus probiotics. Food Microbiol 28: 214-220, 2011.

113. Hoa NT, Baccigalupi L, Huxham A, Smertenko A, Van PH, Ammendola S, Ricca E and Cutting AS: Characterization of Bacillus species used for oral bacteriotherapy and bacterioprophylaxis of gastrointestinal disorders. Appl Environ Microbiol 66: 5241-5247, 2000.

114. Sonenshein AL, Hoch JA and Losick R: Bacillus subtilis and other gram-positive bacteria: biochemistry, physiology, and molecular genetics. American Society for Microbiology, Washington, DC, 1993.

115. Zhang JL, Xie QM, Ji J, Yang WH, Wu YB, Li C, Ma JY and Bi YZ: Different combinations of probiotics improve the production performance, egg quality, and immune response of layer hens. Poult Sci 91: 2755-2760, 2012.

116. van der Aa Kühle A, Skovgaard K and Jespersen L: In vitro screening of probiotic properties of Saccharomyces cerevisiae var. boulardii and food-borne Saccharomyces cerevisiae strains. Int J Food Microbiol 101: 29-39, 2005.

117. Czerucka D, Piche T and Rampal P: Review article: Yeast as probiotics - Saccharomyces boulardii. Aliment Pharmacol Ther 26: 767-778, 2007.

This work is licensed under a Creative Commons Attribution-NonCommercial-NoDerivatives 4.0 International (CC BY-NC-ND 4.0) License. 